\title{
The Analysis of Computer Data regarding Obesity and Associated Diseases in Cats Examined at Private Veterinary Practices
}

\author{
Neşe Kocabağlı', Halil Can Kutay', Banu Dokuzeylül'², İnci Nathalie Erdoğmuş Süer' \& Müjdat Alp
}

\begin{abstract}
Background: Cats can be defined as being overweight if their bodyweight is $15 \%$ above optimum weight and classified as obese if they are more than $30 \%$ above their optimum weight. There is a general agreement among investigators that the incidence of excess body weight in cats is increasing. Obesity has considerable impacts on the health of cats and is linked to a variety of health issues including orthopedic disease, diabetes mellitus and non-allergic skin conditions. The purpose of the present study was to evaluate the relationship between obesity and associated diseases in cats examined at some veterinary practices in Istanbul-Turkey.

Materials, Methods \& Results: Data of 2,272 patients examined at four private veterinary practices in Istanbul was studied to reveal the association between body weight and diseases. Information regarding sex, age and neutering status was also considered for each patient. Patients were classified according to their body weight to three groups as lightweight (female: $3.0 \mathrm{~kg}$ and under, male: $4.5 \mathrm{~kg}$ and under), optimum -weight (female: $3.0-4.5 \mathrm{~kg}$, male: $4.5-5.5 \mathrm{~kg}$ ) and overweight/obese (female: $4.5 \mathrm{~kg}$ and over, male: $5.5 \mathrm{~kg}$ and over). Accounting all adult cats treated by the clinics, diagnoses of osteoarthritis, heart diseases, dermatological diseases, hepatic lipidosis, metabolic syndrome - diabetes mellitus, lameness, gastrointestinal diseases, musculoskeletal diseases, neoplasia and urinary diseases were statistically evaluated. Considering data coming from 2,272 cats, which were referred to veterinary practices, $33.12 \%$, were classified as overweight-obese, $40.04 \%$ were optimum-weight and $26.84 \%$ were lightweight. It was determined that overweight-obese cats were more likely to be diagnosed with osteoarthritis and hepatic lipidosis compared to other groups $(P<0.05)$. Overweight-obese cats were more likely to be diagnosed with gastrointestinal disease and neoplasia compared to lightweight cats $(P<0.05)$.

Discussion: Obesity in cats is very common and the prevalence of combined overweight and obesity has been reported on a range from $20 \%$ to $40 \%$ in developed countries. Associated with the increasing welfare, as in humans, the incidence of obesity in the pet population is also increasing. The data studied for this research was evaluated with regard to diseases associated with obesity. It was determined that overweight-obese cats were more likely to be diagnosed with osteoarthritis and hepatic lipidosis compared to the other groups $(P<0.05)$. Overweight-obese cats were more likely to be diagnosed with gastrointestinal disease and neoplasia compared to lightweight cats $(P<0.05)$. However, an association between overweight or obesity and heart disease, metabolic syndrome - diabetes mellitus, lameness, musculoskeletal disease or urinary diseases was not found. A percentage of 19.95 of the patients over 2 years of age were classified in the overweight-obese group. These findings require that weight gain needs to be prevented before the animals reach obese status. Dietary management and physical exercise are essential for managing obesity in pets. In this study, it was aimed to explain the importance of weight management in preventing overweight or obesity associated diseases to cat owners by using the results, which demonstrate that overweight or obese animals are statistically more likely to develop associated diseases. Veterinary practitioners can also use this data to strongly advocate for the maintenance of feline patients at ideal body condition.
\end{abstract}

Keywords: feline nutrition, overweight/obesity, diseases. 


\section{INTRODUCTION}

Obesity is a medical condition in which excessive amounts of adipose tissue in the body that it may have some negative effects on the health of companion animals $[2,12,14,21]$. Although incidence estimates vary depending upon the population that is surveyed and the methodology used, there is consensus that between $20 \%$ and $40 \%$ of cats living in homes are overweight or obese in developed countries [1$5,13,18,21]$. Associated with the increasing welfare, as in humans, the incidence of obesity in the pet population is also increasing.

The relationship between obesity and the development of diseases in cats is of much clinical interest, but has been the subject of limited research. In order to determine the prevalence rate of overweight/obesity of cats in Japan, 190 cats were examined, out of which $14 \%$ were overweight while $42 \%$ were obese, with an overall prevalence rate of $56 \%$ for being overweight/obese [15].

Obesity in cats is associated with an increased risk of medical complications, such as diabetes mellitus, orthopedic disease, and non-allergic skin conditions [7]. Furthermore, a number of metabolic changes occur, which may not be obvious on routine clinical or laboratory evaluation. For example, obesity can induce a low-grade inflammatory response $[8,20]$. It is therefore highly important for clinicians and owners regularly to monitor weight changes and initiate proper action to prevent or treat unwanted weight gain.

Many clinical veterinarians in Turkey feel that feline obesity is increasing in prevalence within Turkey. However, there is no available data regarding domestic overweight or obese cats being readily available in Turkey. The aim of the present study was to evaluate the relationship between overweight/obesity and associated diseases in cats examined at some veterinary practices in Istanbul-Turkey.

\section{MATERIALS AND METHODS}

\section{Animals}

Data of 2,272 patients examined at four private veterinary clinics in Istanbul-Turkey during 2014 and 2015 was studied to reveal the association between body weight and diseases. Information regarding sex, age and neutering status was also considered for each patient. Patients were classified according to their body weight into three groups as lightweight (female: $3.0 \mathrm{~kg}$ and under, male: $4.5 \mathrm{~kg}$ and under), optimum -weight (female: $3.0-4.5 \mathrm{~kg}$, male: $4.5-5.5 \mathrm{~kg}$ ) and overweight/obese (female: $4.5 \mathrm{~kg}$ and over, male: 5.5 $\mathrm{kg}$ and over). Accounting all adult cats treated by the clinics, diagnoses of osteoarthritis, heart diseases, dermatological diseases, hepatic lipidosis, metabolic syndrome - diabetes mellitus, lameness, gastrointestinal diseases, musculoskeletal diseases, neoplasia and urinary diseases were statistically evaluated.

\section{Statistical methods}

The adult cat population was defined as animals over 1 year of age; analyses were conducted on cats that had at least one diagnosis (including "Healthy") of any kind recorded over the study period. Associations between body weights and diseases were evaluated using the $\chi^{2}$ test (Chi-square analyses). The significance level was set at $P<0.05$.

\section{RESULTS}

A total of 2,772 adult cats along with their reported body weights from four clinics were included in this study. 1,574 of these cats were "healthy" animals without any diseases and 1,198 cats were reported to have at least one disease in category. According to the data of 2,772 cats that were referred to veterinary polyclinics, $26.84 \%$ (744 cats) were lightweight, $40.04 \%$ (1110 cats) were optimum-weight and $33.12 \%$ (918 cats) were overweight-obese (Data not shown).

Prevalence of individual disease and disease categories according to their body weight is detailed in Table 1. It was determined that overweight-obese cats were more likely to be diagnosed with osteoarthritis and hepatic lipidosis compared to other groups $(P<$ 0.05). Overweight-obese cats were more likely to be diagnosed with gastrointestinal disease and neoplasia compared to lightweight cats $(P<0.05)$ [Table 1].

Dermatological diseases, urinary disease, and gastrointestinal disease were the most common diseases for overweight/obese female cats and urinary disease, dermatological diseases, and gastrointestinal disease were the most common diseases for overweight/obese male cats included in this analysis, respectively (Table 2). It was determined that neutered overweight-obese female and male cats were more likely to be diagnosed with diseases compared to intact overweight-obese female and male cats, in this study (Figure 1). 
Table 1. Disease and disease category* prevalence by body weight category for adult cats $(\mathrm{n}=1,198)$.

\begin{tabular}{|c|c|c|c|c|c|c|c|}
\hline \multirow[t]{2}{*}{ Disease } & \multicolumn{2}{|c|}{$\begin{array}{l}\text { Light weight } \\
\mathrm{n}=295\end{array}$} & \multicolumn{2}{|c|}{$\begin{array}{c}\text { Optimum weight } \\
n=440\end{array}$} & \multicolumn{2}{|c|}{$\begin{array}{c}\text { Overweight/obese } \\
n=463\end{array}$} & \multirow[t]{2}{*}{$P$ Value } \\
\hline & $\mathrm{n}$ & $\%$ & $\mathrm{n}$ & $\%$ & $\mathrm{n}$ & $\%$ & \\
\hline Osteoarthritis & 0 & $0.0 \mathrm{~b}$ & 2 & $0.2 b$ & 8 & $0.9 \mathrm{a}$ & 0.006 \\
\hline Heart disease & 7 & 0.9 & 18 & 1.6 & 12 & 1.3 & 0.455 \\
\hline Dermatopathy & 80 & $10.8 \mathrm{ab}$ & 103 & $9.3 b$ & 127 & $13.8 \mathrm{a}$ & 0.005 \\
\hline Hepatic Lipidosis & 4 & $0.5 b$ & 3 & $0.3 b$ & 20 & $2.2 \mathrm{a}$ & 0.001 \\
\hline Diabetes Mellitus & 12 & 1.6 & 29 & 2.6 & 24 & 2.6 & 0.304 \\
\hline Lameness & 2 & 0.3 & 14 & 1.3 & 7 & 0.8 & 0.067 \\
\hline Gastrointestinal Disease & 84 & $9.2 \mathrm{~b}$ & 128 & $11.5 \mathrm{ab}$ & 104 & $14.0 \mathrm{a}$ & 0.009 \\
\hline Musculoskeletal Disease & 0 & 0.0 & 1 & 0.1 & 2 & 0.2 & 0.394 \\
\hline Neoplasia & 1 & $0.1 b$ & 7 & $0.6 \mathrm{ab}$ & 13 & $1.4 \mathrm{a}$ & 0.009 \\
\hline Urinary Disease & 105 & 14.1 & 135 & 12.2 & 146 & 15.9 & 0.052 \\
\hline
\end{tabular}

*Cat was reported to have at least 1 disease in category. a-bMeans within columns with different superscripts, differ significantly important. $(P<0.05)$.

Table 2. Disease and disease category* prevalence by body weight category for female and male cats.

\begin{tabular}{|c|c|c|c|c|c|c|}
\hline \multirow[b]{2}{*}{ Disease } & \multicolumn{3}{|c|}{ Female } & \multicolumn{3}{|c|}{ Male } \\
\hline & $\begin{array}{l}\text { Lightweight } \\
\leq 3.0 \mathrm{~kg}\end{array}$ & $\begin{array}{c}\text { Optimum-weight } \\
3.0-4.5 \mathrm{~kg}\end{array}$ & $\begin{array}{c}\text { Overweight/obese } \\
4.5 \mathrm{~kg} \geq\end{array}$ & $\begin{array}{l}\text { Lightweight } \\
\leq 4.5 \mathrm{~kg}\end{array}$ & $\begin{array}{c}\text { Optimum-weight } \\
4.5-5.5 \mathrm{~kg}\end{array}$ & $\begin{array}{c}\text { Overweight/obese } \\
5.5 \mathrm{~kg} \geq\end{array}$ \\
\hline Osteoarthritis & 0 & 2 & 3 & 0 & 0 & 5 \\
\hline Heart disease & 1 & 8 & 4 & 6 & 10 & 8 \\
\hline Dermatopathy & 27 & 54 & 53 & 53 & 49 & 74 \\
\hline Hepatic Lipidosis & 1 & 1 & 10 & 3 & 2 & 10 \\
\hline Diabetes Mellitus & 7 & 20 & 10 & 5 & 9 & 14 \\
\hline Lameness & 1 & 7 & 1 & 1 & 7 & 6 \\
\hline $\begin{array}{l}\text { Gastrointestinal } \\
\text { Diseases }\end{array}$ & 42 & 81 & 44 & 42 & 47 & 60 \\
\hline $\begin{array}{l}\text { Musculoskeletal } \\
\text { Disease }\end{array}$ & 0 & 0 & 1 & 0 & 1 & 1 \\
\hline Neoplasia & 0 & 3 & 6 & 1 & 4 & 7 \\
\hline Urinary Disease & 19 & 44 & 46 & 86 & 91 & 100 \\
\hline
\end{tabular}

*Cat was reported to have at least 1 disease in category.

\section{DISCUSSION}

Out of 2,772 cats examined in the study, $26.84 \%$ (744 cats) were lightweight, $40.04 \%$ (1110 cats) were optimum-weight and $33.12 \%$ (918 cats) were classified as overweight-obese (Data not shown). The results of the present study are in line with the results of a previous study which reported $35 \%$ overweight and obesity in adult cats seen by US veterinarians during 1995 [13]. However, obesity rate in some other studies in the United Kingdom (52\%) [17], and in Japan (56\%) [15], are nearly double. For cats, as for humans, obesity is a multifactorial problem, and some of the factors are similar between the species. A number of potentially related risk factors may be relevant including genetics, sex status, age, owner characteristics and behaviors [3]. It has previously been shown that owners tend to underestimate the condition of their pet, especially if the pet is overweight [11]. Living a sedentary lifestyle, along with being overfed highly palatable and energy-dense foods, may also be important contributing factors [21]. 


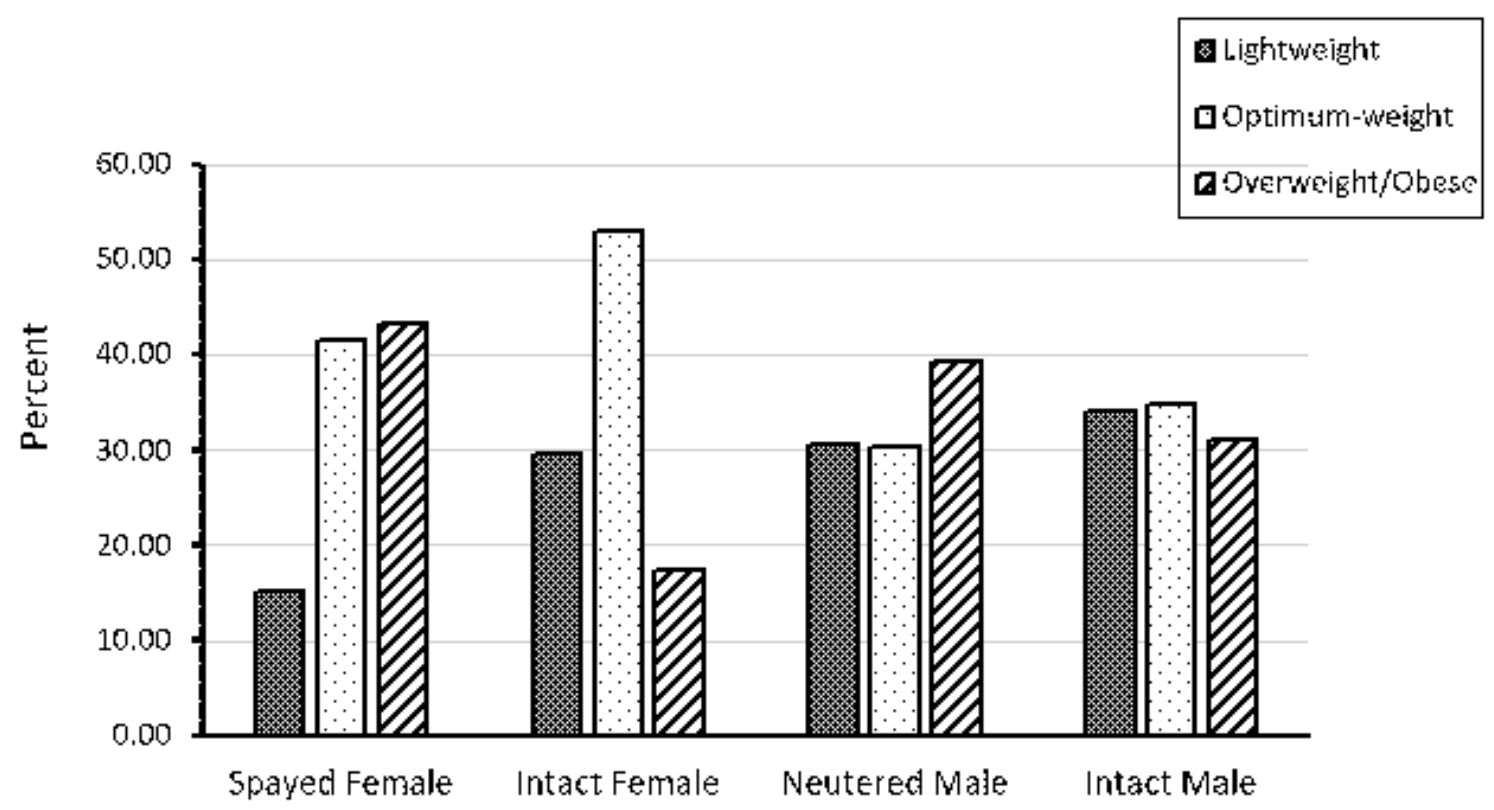

Figure 1. Prevalence of body weight category by gender for adult sick cats.

In cats, obesity is a strong risk factor for the development of diabetes as it results in insulin resistance and hyperinsulinemia [16]. Obese cats were found to be 3.9 times more likely to develop diabetes, 4.9 times more likely to develop lameness and 2.3 times more likely to have non-allergic skin conditions, compared to cats of optimal body condition [19]. However in this study, it was determined that overweight-obese cats were more likely to be diagnosed with osteoarthritis and hepatic lipidosis compared to other groups $(P<$ $0.05)$. In addition, overweight-obese cats were more likely to be diagnosed with gastrointestinal disease and neoplasia compared to lightweight cats $(P<0.05)$ [Table 1]. The study reported here has been accomplished with the use of computerized information systems by private veterinary clinics. Therefore, these information systems are based on an accounting paradigm.

Dermatological diseases, urinary disease, and gastrointestinal disease were the most common diseases for both female and male cats included in this analysis (Table 2). Overweight cats are at increased risk for urinary tract diseases; however, a relationship between obesity and urinary diseases as a category was not found, possibly due to lack of statistical power.

Neutering is an important risk factor for obesity in cats; many studies suggested that this is due to a decrease in metabolic rate after neutering $[6,10]$. Althou$\mathrm{gh}$, increased fat mass is usually present in neutered animals; when energy expenditure is expressed on a lean mass basis; no difference in metabolic rate is no- ted between neutered and entire individuals [9]. It was determined that neutered overweight-obese cats were more likely to be diagnosed with diseases compared to intact overweight-obese cats, in this study (Figure 1).

In conclusion, our findings demonstrate that the prevalence of obesity in cats was high within a population of cats visiting a veterinary practice and dermatological diseases, urinary diseases, and gastrointestinal diseases were the most common diseases for overweight/obese cats. With the results of this study, veterinarians should be able to better focus on what is important for the cat population. However, the results of the prevalence analyses need to be interpreted with caution, as the study population may not necessarily be representative of the general population throughout Turkey. Electronic tools for capturing data and information systems are becoming increasingly sophisticated; perhaps with the adaptation of fully integrated information systems, these type of studies will be more feasible.

\section{CONCLUSION}

Obesity is a growing concern in household pet animals, and the increasing incidence appears to be mirroring the trend observed in their owners. The major medical concern of obesity relates to many diseases and disease categories that accompany adiposity. These conditions not only shorten the expected lifespan of the affected animals, but also reduce their health-related quality of life. Therefore, there is a need to increase 
N. Kocabağlı, H.C. Kutay, B. Dokuzeylül, I.N.E. Süer \& M. Alp. 2017. The Analysis of Computer Data regarding Obesity and Associated Diseases in Cats Examined at Private Veterinary Practices. Acta Scientiae Veterinariae. 45: 1506.

awareness within the veterinary profession and pet owners that obesity in companion animals is a serious medical concern.

Acknowledgements. The authors would like to thank the four veterinary clinics in İstanbul-Turkey (Axis Veterinary Clinic,
VetArt Veterinary Clinic, Vet Axis Veterinary Clinic, and Tilia Veterinary Clinic) for their assistances in gathering the data.

Declaration of interest. The authors report no conflicts of interest. The authors alone are responsible for the content of the paper.

\section{REFERENCES}

1 Armstrong P.J. \& Lund E.M. 1996. Changes in body composition and energy balance with aging. Veterinary Clinical Nutrition. 3: 83-87.

2 Burkholder W.J. \& Toll P.W. 2000. Obesity. In: Hand M.S., Thatcher C.D., Reimillard R.L., Roudebush P., Morris M.L. \& Novotny B.J. (Eds). Small Animal Clinical Nutrition. 4th edn. Topeka: Mark Morris Institute, pp.401-430.

3 Cave N.J., Allan F.J., Schokkenbroek S.L., Metekohy C.A. \& Pfeiffer D.U. 2012. A cross-sectional study to compare changes in the prevalence and risk factors for feline obesity between 1993 and 2007 in New Zealand. Preventive Veterinary Medicine. 107(1-2): 121-133.

4 Colliard L., Paragon B.M., Lemuet B., Bénet J.J. \& Blanchard G. 2009. Prevalence and risk factors of obesity in an urban population of healthy cats. Journal of Feline Medicine and Surgery. 11(2): 135-140.

5 Courcier E.A., O'Higgins R., Mellor D.J. \& Yam P.S. 2010. Prevalence and risk factors for feline obesity in a fist opinion practice in Glasgow, Scotland. Journal of Feline Medicine and Surgery. 12(10): 746-753.

6 Fettman M.J., Stanton C.A. \& Banks L.L. 1997. Effects of neutering on body weight, metabolic rate and glucose tolerance in domestic cats. Research in Veterinary Science. 62(2): 131-136.

7 German A.J. 2006. The Growing Problem of Obesity in Dogs and Cats. Journal of Nutrition. 136: 1940S-1946S.

8 German A.J., Ryan V.H., German A.C., Wood I.S. \& Trayhurn P. 2010. Obesity, its associated disorders and the role of inflammatory adipokines in companion animals. Veterinary Journal. 185(1): 4-9.

9 Harper E.J., Stack D.M., Watson T.D.G. \& Moxham G. 2001. Effect of feeding regimens on body weight, composition and condition score in cats following ovariohysterectomy. Journal of Small Animal Practice. 42(9): 433-438.

10 Hoenig M. \& Ferguson D.C. 2002. Effects of neutering on hormonal concentrations and energy requirements in cats. American Journal of Veterinary Medical Research. 63: 634-639.

11 Kienzle E. \& Bergler R. 2006. Human-animal relationship of owners of normal and overweight cats. Journal of Nutrition. 136: 1947S-1950S.

12 Kopelman P.G. 2000. Obesity as a medical problem. Nature. 404(6778): 635-643.

13 Lund E.M., Armstrong P.J., Kirk C.A. \& Klausner J.S. 2005. Prevalence and risk factors for obesity in adult cats from private US veterinary practices. The International Journal of Applied Research in Veterinary Medicine. 3(2): 88-96.

14 McGreevy P.D., Thomson, P.C., Pride C., Fawcett A., Grassi T. \& Jones B. 2005. Prevalence of obesity in dogs examined by Australian veterinary practices and the risk factors involved. Veterinary Record. 156: 695-702.

15 Mori N., Iwasaki E., Okada Y., Kawasumi K. \& Arai T. 2016. Overall prevalence of feline overweight/obesity in Japan as determined from a cross-sectional sample pool of healthy veterinary clinic-visiting cats in Japan. Turkish Journal of Veterinary Animal Science. 40: 304-312.

16 Öhlund M., Egenvall A., Fall T., Hansson-Hamlin H., Röcklinsberg H. \& Holst B.S. 2017. Environmental Risk Factors for Diabetes Mellitus in Cats. Journal of Veterinary Internal Medicine. 31(1): 29-35.

17 Russell K., Sabin R., Holt S., Bradley R. \& Harper E.J. 2000. Influence of feeding regimen on body condition in the cat. Journal of Small Animal Practice. 41(1): 12-17.

18 Scarlett J.M., Donoghue S., Saidla J. \& Wills J. 1994. Overweight cats: prevalence and risk factors. International Journal of Obesity and Related Metabolic Disorders. 18(S1): S22-S28.

19 Scarlett J.M. \& Donoghue S. 1998. Associations between body condition and disease in cats. Journal of the American Veterinary Medical Association. 212: 1725-1731.

20 Trayhurn P. 2005. Adipose tissue in obesity-an inflammatory issue. Endocrinology 146(3): 1003-1005.

21 Wolfsheimer K.J. 2000. Obesity. In: Ettinger S.J. \& Feldman E.C. (Eds). Textbook of Veterinary Internal Medicine. Philadelphia: W.B. Saunders Co., pp.70-72.

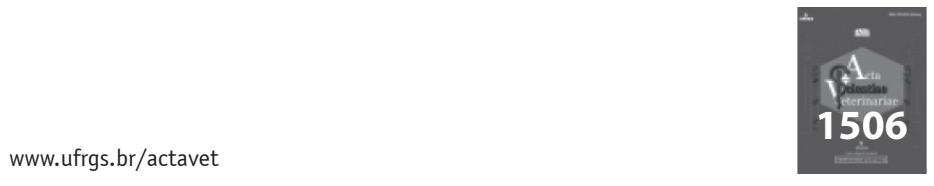

